\title{
Flow limitation and dynamic hyperinflation: key concepts in modern respiratory physiology
}

\author{
P.M.A. Calverley* and N.G. Koulouris"
}

ABSTRACT: Fashions in ideas, like clothes, come and go. From approximately 1950-1980, physiological research was seen as the key discipline in understanding lung disease and was at the cutting edge of pulmonary science. Subsequently, its importance has been down played amid a widely accepted but unfounded assumption that we now have a perfect working understanding of the physiological behaviour of the respiratory system in health and disease. Although it seems improbable that completely new disciplines within respiratory physiology will emerge with fundamentally different ways of describing the mechanical or gas exchanging function of the lung, advances in computing and new observations in disease have highlighted previously unsuspected physiological abnormalities that have changed the way we view lung disease and the interface between disordered lung mechanics, symptomatology and disability.

This is especially true for the two related physiological concepts of expiratory flow limitation and dynamic hyperinflation, which are now being taken from the physiological laboratory to the bedside with dramatic effect. Each arises from well-established theoretical and practical observations first made $\mathbf{4 0}$ yrs ago and now adapted to a range of settings, particularly in the field of obstructive lung disease. This review focuses on how these conditions are defined and assessed and what evidence there is that they might be important in lung disease.

KEYWORDS: Asthma, chronic obstructive pulmonary disease, exercise, flow limitation, hyperinflation, physiological concepts

\section{TIDAL EXPIRATORY FLOW LIMITATION AND ITS MEASUREMENT \\ Conventional techniques}

The term expiratory flow limitation (EFL) is used to indicate that maximal expiratory flow is achieved during tidal breathing and it is characteristic of intrathoracic airflow obstruction. It should be noted that some experts use the term chronic airflow limitation as a synonym for chronic obstructive pulmonary disease (COPD), to indicate the reduction in maximum expiratory flow that occurs in this disease (and indeed in other pulmonary diseases); however, this term does not imply that EFL actually occurs during tidal breathing [1-3].

The presence of EFL during tidal breathing promotes dynamic pulmonary hyperinflation $(\mathrm{DH})$ and intrinsic positive end-expiratory pressure $(\mathrm{PEEP})$, with concomitant increase of work of breathing, functional impairment of inspiratory muscle function and adverse effects on haemodynamics [4]. This, together with flow-limiting dynamic airway compression during tidal breathing, may contribute to dyspnoea [5].

\section{AFFILIATIONS}

*Clinical Science Centre, University Hospital Aintree, Liverpool, UK. \#Respiratory Function Laboratory, Dept of Respiratory Medicine, University of Athens Medical School, "Sotiria" Hospital, Athens, Greece.

CORRESPONDENCE

N.G. Koulouris

Respiratory Function Laboratory Dept of Respiratory Medicine

University of Athens Medical School "Sotiria" Hospital

Athens

Greece

Fax: 302107223420

E-mail: koulnik@med.uoa.gr

Received:

September 302004

Accepted:

October 122004 
According to a recently proposed attractive and provocative hypothesis [6], the transition from peripheral airway disease to overt COPD in smokers who are destined to develop COPD is characterised by three sequential stages, in which EFL plays a central role: Stage I, the closing volume eventually exceeds the functional residual capacity; Stage II, EFL first develops; and Stage III, DH progressively increases, leading to dyspnoea and exercise limitation. The presence of airway closure (Stage I) and EFL (Stage II) in the tidal volume range may promote peripheral airway injury and accelerate the abnormalities of lung function [7-9]. This enhances inflammation due to smoke per se, leading to severe functional and structural abnormalities within the lung. This vicious cycle cannot be reversed, possibly apart from in Stage I.

Despite the severe consequences of EFL, the prevalence and clinical significance of this phenomenon have not been adequately studied in COPD, asthma and patients with other pulmonary and nonpulmonary disease.

By definition, finding of EFL requires the demonstration of an increase in transpulmonary pressure with no increase in expiratory flow. Therefore, direct assessment of EFL requires determination of iso-volume relationships between flow and transpulmonary pressure, an approach that is the gold standard. However, this method is technically complex, time consuming and invasive, because it requires the passage of an oesophageal balloon [10,11].

Until recently, the conventional method used to detect EFL during tidal breathing was one proposed by HyAтT [3] in 1961. It consists of correctly superimposing a flow-volume loop of a tidal breath within a maximum flow-volume curve. This analysis and the "concept of EFL" have been the kernel for understanding respiratory dynamics. EFL is not present when the patient breathes below the maximal expiratory flowvolume (MEFV) curve. According to this technique, normal subjects do not reach EFL, even at maximum exercise $[1,2]$. In contrast, EFL is present when a patient seeks to breathe tidally along or higher than the MEFV curve. It has long been suggested that patients with severe COPD may exhibit EFL even at rest, as reflected by the fact that they breathe tidally along or above their MEFV curve [1-6]. However, the conventional method to detect ELF, based on the comparison MEFV and tidal expiratory flow-volume curves, has several methodological deficiencies. These include the following. 1) Thoracic gas compression artefacts. To minimise such errors, volume should be measured with a body plethysmograph, instead of using, as is common practice, a pneumotachograph or a spirometer [12]. The corollary of this is that, in practice, EFL may be assessed only in seated subjects at rest. 2) Incorrect alignment of tidal expiratory flow-volume and MEFV curves. Such alignment is usually made considering the total lung capacity (TLC) as a fixed reference point. This assumption may not always be valid [13, 14]. 3) Effect of previous volume and time history. Since the previous volume and time history of a spontaneous tidal breath is necessarily different from that of a forced vital capacity (FVC) manoeuvre, it is axiomatic that comparison of tidal expiratory flow-volume with MEFV curves is problematic. In fact, there is not a single MEFV curve, but rather a family of different curves, which depend on the time-course of the inspiration preceding the FVC manoeuvre [15-17]. Therefore, comparison of tidal expiratory flow-volume and MEFV curves is incorrect. 4) Respiratory mechanics and time constant inequalities are different during the tidal and maximal expiratory efforts, also making comparisons of the two flow-volume curves problematic [1820]. 5) Exercise may result in bronchodilation or bronchoconstriction and other changes of lung mechanics, which may also affect correct comparisons of the two flow-volume curves [21]. 6) Patient cooperation. Another important limitation of the conventional method is that it requires patient cooperation. This is not always feasible [13, 14].

From the above considerations, it appears that the detection of EFL based on comparison of tidal expiratory flow-volume with MEFV curves is not valid, even when a body-box is used. In fact, this has been clearly demonstrated in several studies [22-25]. As a result, the use of the conventional method is no longer recommended.

\section{The negative expiratory pressure technique}

Recently, in order to overcome the technical and conceptual difficulties discussed above, the negative expiratory pressure (NEP) method has been introduced [22-25] (fig. 1). The NEP technique has been applied and validated in mechanically ventilated intensive care unit (ICU) patients by concomitant determination of iso-volume flow-pressure relationships [23, 26] (fig. 2). This method does not require FVC manoeuvres, collaboration on the part of the patient or use of a body plethysmograph, and can be used during spontaneously breathing subjects in any body position [27], during exercise $[24,28,29]$ and in an ICU setting [7, 8, 23, 30-32]. With this method, the volume and time history of the control and test expiration are the same.

Figure 1 depicts the experimental set-up used to assess EFL [22]. A flanged plastic mouthpiece is connected in series to a pneumotachograph and a T-tube. One side of the T-tube is open to the atmosphere, whilst the other side is equipped with a one-way pneumatic valve, which allows for the subject to be rapidly switched to negative pressure generated by a vacuum cleaner or a Venturi device. The pneumatic valve consists of an inflatable balloon connected to a gas cylinder filled with helium and a manual pneumatic controller. The latter permits remote-control balloon deflation, which is accomplished quickly (30-60 ms) and quietly, allowing rapid exposure to NEP. Alternatively, a solenoid rapid valve can be used. The NEP (usually set at about -3 to $-5 \mathrm{cmH}_{2} \mathrm{O}$ ) can be adjusted with

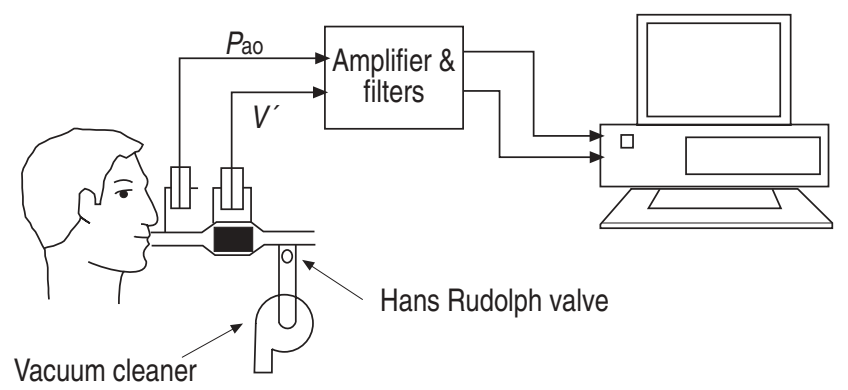

FIGURE 1. Schematic diagram of equipment setup. Pao: airway opening pressure; $V^{\prime}$ : flow. Figure reproduced with permission from [22]. 

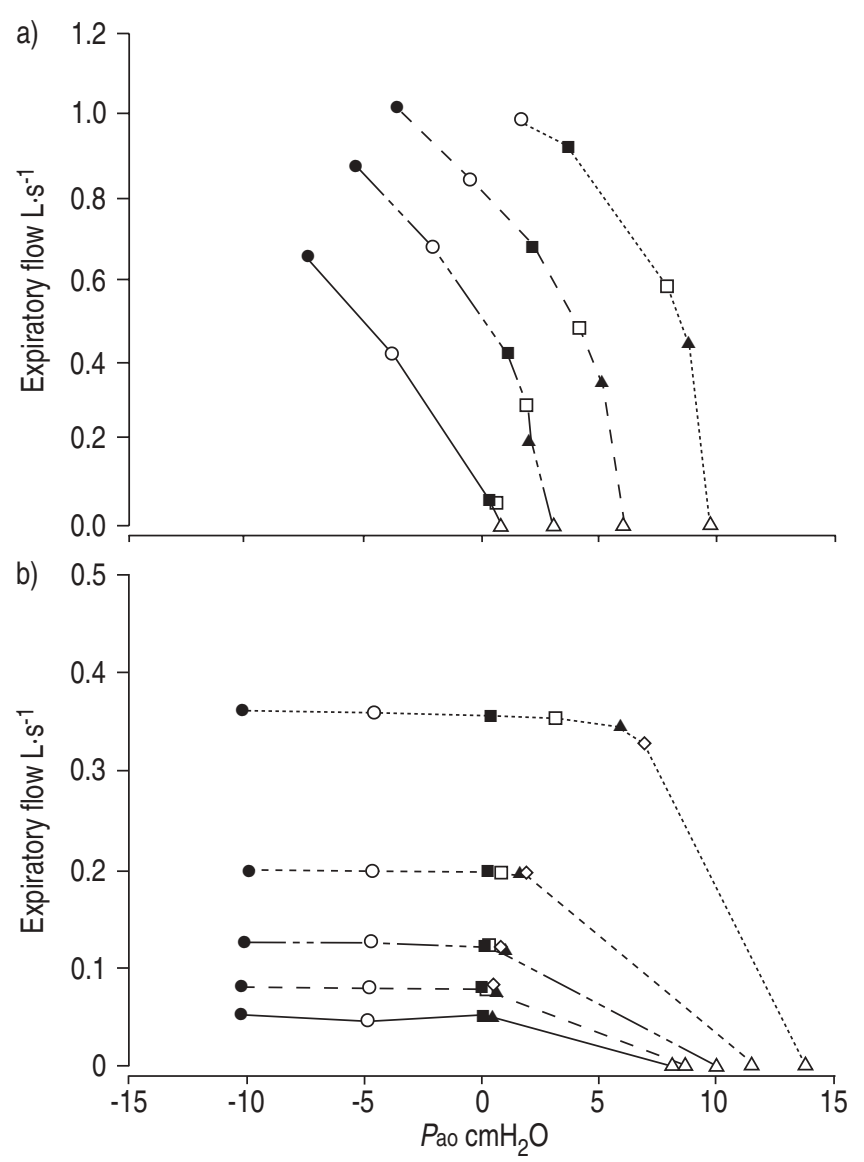

FIGURE 2. Expiratory iso-volume flow-airway opening pressure $(P$ ao) relationships under control conditions and during test breaths with different methods to assess flow limitation in two mechanically ventilated patients. - negative expiratory pressure (NEP) of $-10 \mathrm{cmH}_{2} \mathrm{O}$; $\mathrm{O}$ : NEP of $-5 \mathrm{cmH}_{2} \mathrm{O}$; $\mathbf{\square}$ : expiration into atmosphere (ATM); $\boldsymbol{\Lambda}$ and $\diamond$ : expiration with added expiratory resistance; $\triangle$ : static pressure of respiratory system during lung deflation. a) Representative nonflow-limited patient, as indicated by the increase in flow with NEP and ATM compared with control. —- no change in volume $(\Delta V) ;----: 0.2 \mathrm{~L} \Delta V$; - - - : $0.4 \mathrm{~L} \Delta V ; \cdots \cdots: 0.6 \mathrm{~L} \Delta V$. b) Representative expiratory flow-limited patient, as indicated by unchanged expiratory flow and ATM compared with control. —: $0 \Delta V$; - -: $0.1 \mathrm{~L} \Delta V$; - - - -: $0.2 \mathrm{~L} \Delta V_{\text {; }}-$ - - - : $0.3 \mathrm{~L} \Delta V_{;} ; \cdots \cdots: 0.4 \mathrm{~L} \Delta V$. Figure reproduced with permission from [23].

a potentiometer on the vacuum cleaner or by controlling the Ventouri device. Flow is measured with the heated pneumotachograph and pressure at the airway opening is simultaneously measured through a side port on the mouthpiece. Volume is obtained by digital integration of the flow signal [22-25].

While performing the test, the subjects should be watched closely for leaks at the mouthpiece. By monitoring the volume record over time on the chart recorder, the absence of leaks and electrical drift can be ensured by the fact that, after the NEP tests, the end-expiratory lung volume (EELV) returns to the pre-NEP level. Only those tests in which there is no leak are valid [33].

The NEP method is based on the principle that, in the absence of pre-existing flow limitation, the increase in pressure
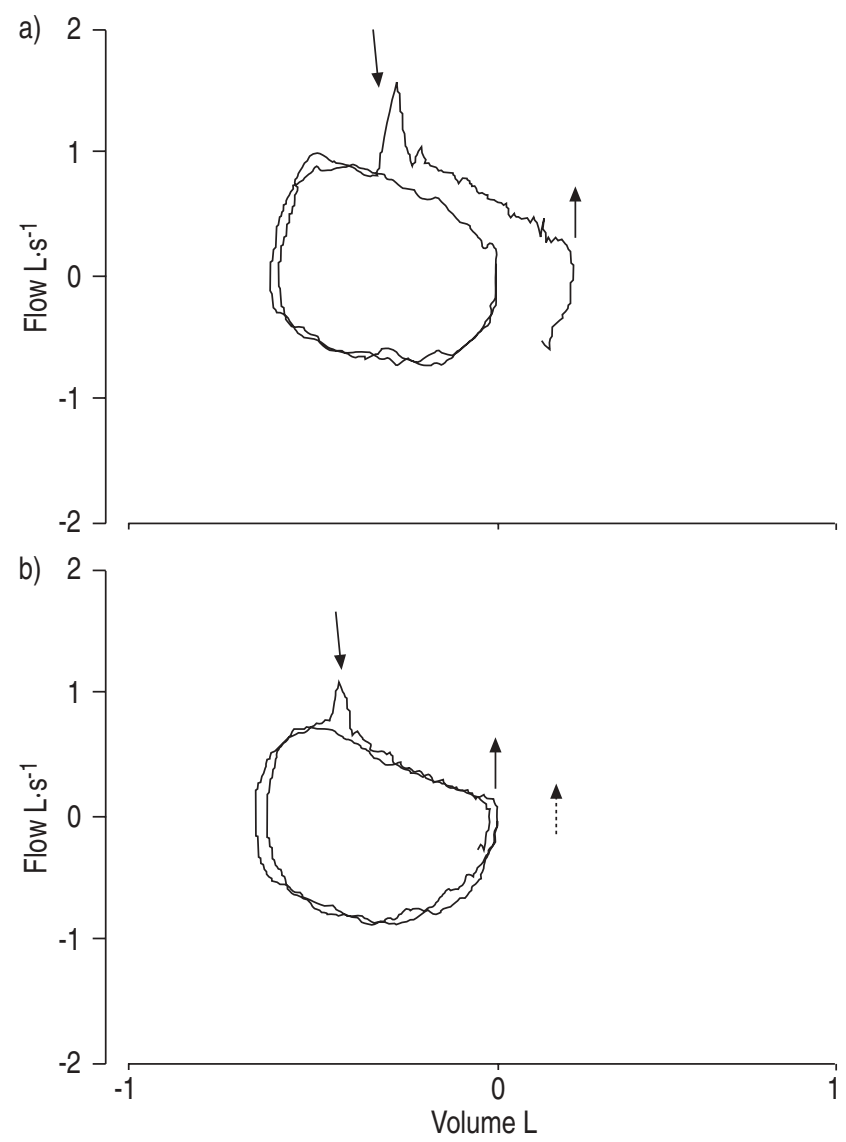

FIGURE 3. Flow-volume loops of test breaths and preceding control breaths of two representative bronchiectatic patients with different degrees of flow limitation: a) not flow limited; and b) flow limited over $<50 \%$ tidal volume. Arrows: negative expiratory pressure applied and removed; dotted arrow: expiration. Figure reproduced with permission from [54].

gradient between the alveoli and the airway opening caused by NEP should result in increased expiratory flow. By contrast, in flow-limited subjects, application of NEP should not change the expiratory flow. The current authors' analysis essentially consists of comparing the expiratory flow-volume curve obtained during a control breath with that obtained during the subsequent expiration in which NEP is applied [22, 23].

Subjects in whom application of NEP does not elicit an increase of flow during part or all of the tidal expiration (fig. 3) are considered to be EFL. By contrast, subjects in whom flow increases with NEP throughout the control tidal volume range are considered as nonflow-limited (NFL). If EFL is present when NEP is applied, there is a transient increase of flow (spike), which mainly reflects a sudden reduction in volume of the compliant oral and neck structures. To a lesser extent, a small artefact, due to common-mode rejection ratio of the system of measuring flow, may also contribute to the flow transients [22-24]. Such spikes are useful markers of EFL.

The degree of flow limitation can be assessed using four different EFL indices: 1) as a continuous variable expressed as per cent tidal volume in both seated and supine positions 

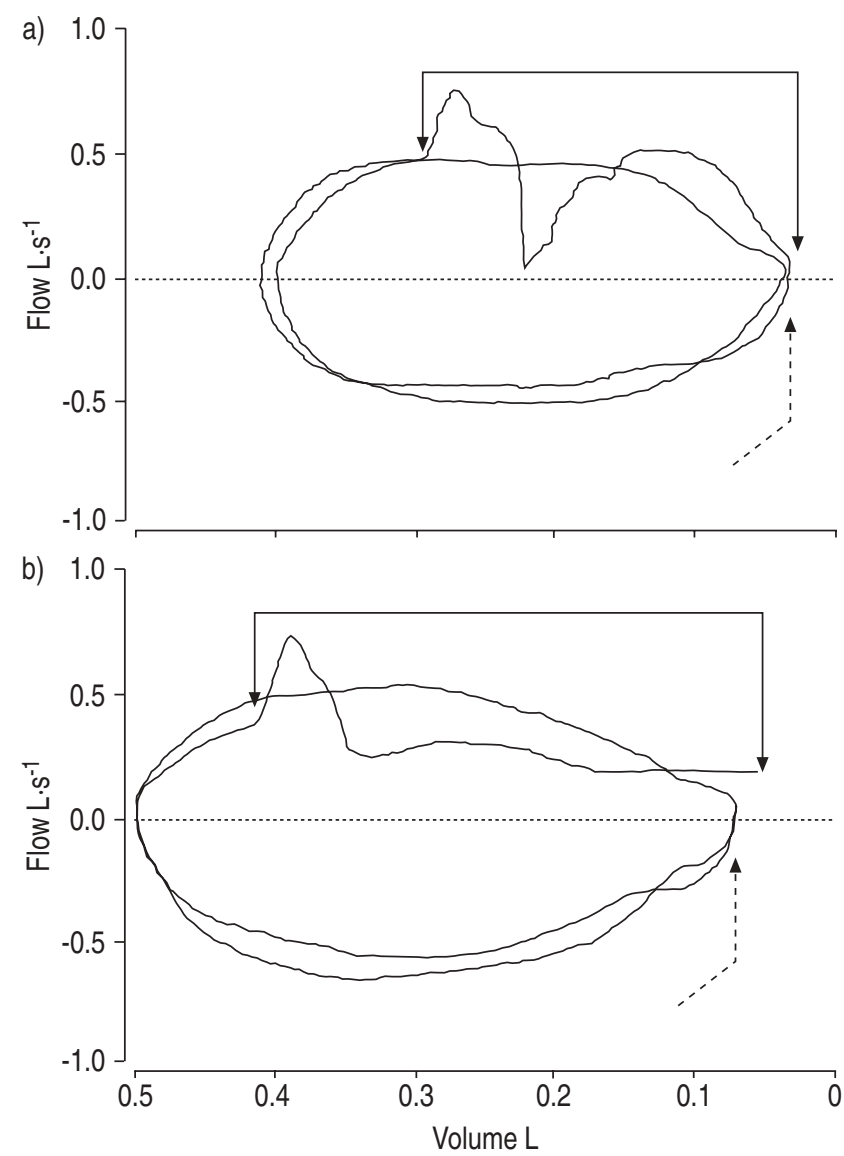

FIGURE 4. Flow-volume loops obtained with negative expiratory pressure (NEP) and preceding control tidal breath in two sitting representative snorers at rest. Arrows: NEP $\left(-5 \mathrm{cmH}_{2} \mathrm{O}\right)$ applied and removed; dotted arrows: forced residual capacity. a) With NEP, expiratory flow shows a transient drop below control flow, reflecting a temporary increase in upper airway resistance. After this transient decrease in flow, expiratory flow with NEP exceeds control flow, showing there is no intrathoracic flow limitation. b) Flow with NEP remained below control throughout expiration, reflecting prolonged increase in upper airway resistance. In this case, NEP test is not valid for assessing intrathoracic flow limitation. However, this phenomenon is uncommon in nonobstructive sleep apnoea-hypopnoea syndrome subjects [37]. Furthermore, valid measurements may be obtained with repeated NEP tests using lower levels of NEP (e.g. $-3 \mathrm{cmH}_{2} \mathrm{O}$ ). Figure reproduced with permission from [34].

(fig. 3) [22]; 3) as a discrete variable in the form of a two classification, i.e. NFL in the seated position, EFL in the seated position 3) as a discrete variable in the form of three categories of classification, i.e. NFL both seated and supine, EFL supine but not seated, EFL both seated and supine [22]; and 4) as a discrete variable in the form of the five-categories classification (five-point EFL score) [25].

Application of NEP is not associated with any unpleasant sensation, cough or other side-effects [22-25]. However, there is a potential limitation of the NEP technique, which concerns normal snorers and patients with obstructive sleep apnoeahypopnoea syndromes (OSAHS) [34-37]. A typical example is clearly illustrated in figure 4.

In non-OSAHS and OSAHS patients [36, 37], in whom there is a consistent upper airway collapse in response to the application of NEP, EFL can be assessed by either submaximal expiratory manoeuvres initiated immediately after end-tidal inspiration or by squeezing the abdomen during expiration (see below).

Turning this apparent drawback into an advantage, LIISTRO et al. [35] and VERIN et al. [36], in OSAHS patients with no evidence of intra-thoracic obstruction, found a significant correlation of the degree of flow limitation, expressed as \% tidal volume in the supine position, with desaturation index and apnoea/hypopnoea index.

\section{Clinical applications}

Since its introduction, the NEP technique has been applied to detect EFL or examine the effect of negative pressure in several studies under different conditions, i.e. different body postures [27], rest and exercise [24, 28, 29], in spontaneously breathing and mechanically ventilated subjects $[7,8,23,30-32]$, paediatric [26, 38], neurological [39] and geriatric settings [40, 41].

In one study, EFL was determined during resting breathing in sitting and supine positions in 117 stable COPD patients [25]. Although, on average, the patients who were experiencing EFL when both seated and supine had a lower forced expiratory volume in one second (FEV1) expressed as per cent predicted than those who were not experiencing EFL, there was a marked scatter of the data. Indeed, $60 \%$ of the NFL group had an FEV $1<49 \%$ pred and were classified as having severe to very severe airway obstruction. Thus, FEV1 is not a specific predictor of EFL in COPD patients.

Intuitively, it would be expected that patients with the most severe airway obstruction, as assessed with routine lung function measurements, would be the most dyspnoeic. However, some patients with severe airway obstruction are minimally symptomatic, whereas others with little objective dysfunction appear to be very dyspnoeic. In fact, many studies have shown that the correlation between chronic dyspnoea and FEV1 is weak. In contrast, EFL measured with the NEP technique is a much better predictor of chronic dyspnoea than FEV1 in COPD patients [25]. Furthermore, it is also shown that there is a high prevalence of orthopnoea in these patients [42].

It appears that in stable COPD patients, there is a high prevalence of EFL, even when taking into account the severity of airways obstruction in terms of FEV1. Indeed, $48 \%$ of COPD patients were EFL as compared with $15 \%$ of stable asthmatics at comparable FEV1 values [22, 25, 42-44]. In contrast with COPD patients, most asthmatics do not exhibit EFL during resting breathing seated and/or supine [28, 42-46]. This discrepancy between asthma and COPD may reflect a lower elastic recoil in the latter condition.

TANTUCCI et al. [43] were the first to assess the effect of a bronchodilator (salbutamol) on resting inspiratory capacity (IC). In a group of COPD patients, divided according to the presence or absence of tidal EFL and with similar baseline FEV1 \% pred, the acute administration of a bronchodilator induced a significant ( $>10 \%$ of baseline) increase in IC only in the tidally EFL COPD patients ( $~ 75 \%$ of these patients). It should be remembered that only 6\% (European Respiratory Society criteria) or $16 \%$ (American Thoracic Society criteria) of all COPD patients examined have reversibility of airway 
obstruction after bronchodilator. Moreover, a significant postbronchodilator decrease in EELV (or dynamic functional residual capacity) was observed only in the COPD subgroup with tidal EFL.

Subsequently, it has been shown that the increase in IC after anticholinergic and salbutamol therapy best reflects the improvement in exercise tolerance [47]. Both a significant reduction in exertional dyspnoea ( $\Delta$ Borg,exercise) and a close relationship between $\Delta$ Borg,exercise (decrease) and $\Delta \mathrm{IC}$ at rest (\% pre) (increase) were found after salbutamol, regardless of the change in FEV1, in the group of COPD patients with tidal EFL at rest. In contrast, no change in $\triangle \mathrm{IC}$ at rest (\% pre) and in $\Delta$ Borg,exercise was observed in the group of COPD patients without tidal EFL at rest. Therefore, in COPD patients, the reduction in breathlessness during mild-to-moderate exercise following the administration of a bronchodilator is heralded by an increase in IC at rest.

The improvement of IC after bronchodilator administration, which is mainly limited to patients with EFL at rest and who exhibit a reduction of baseline IC, entails reduction in dyspnoea both at rest and during light exercise [47]. Thus, in obstructive lung disease, the benefit of bronchodilator therapy should be assessed not only in terms of changes in FEV1, but, more importantly, also in terms of increases in IC. In this context it should be noted that, since performance of IC precedes the FVC manoeuvre, FEV1 and IC are, in general, recorded together during bronchodilator testing.

Although bronchodilator testing has traditionally focused on changes in FEV1, the scrutiny of changes in IC should be mandatory, because it provides more useful information than FEV1 pertaining to dyspnoea and exercise tolerance. The detection of EFL alone with the NEP technique is not an appropriate measurement of acute bronchodilator responsiveness [48]. However, the fact that after bronchodilator administration there is a significant reduction of DH only in patients with EFL at rest in the sitting position further supports the usefulness of stratifying COPD patients in subgroups with and without EFL in order to predict an improvement in $\mathrm{DH}$. Thus, measurement of IC and detection of EFL are complimentary ways for assessing bronchodilator responsiveness in COPD patients $[43,47]$.

The current authors have previously studied the feasibility of using the NEP technique during exercise and have assessed the implications of EFL on exercise performance [24, 28, 29]. Figure 5 shows flow-volume curves of a COPD patient both at rest and two levels of exercise [24]. With NEP, flow increased at rest, but not during exercise, indicating that EFL was present at both levels of exercise but not at rest. With the conventional test, i.e. comparing the tidal flow-volume to the MEFV curve, this patient would be classified as EFL at rest and during exercise. The NEP method has a great advantage, in that it allows for all the effects discussed earlier, including bronchoconstriction or bronchodilation occurring during exercise [28]. In this context, using the NEP test, MURCIANo et al. [29] were able to show that, although patients after single lung transplantation were not flow limited at rest, most become flow limited during exercise.

Figure 6 shows subdivisions of lung volume, expressed as per cent of TLC, at rest and different exercise levels in three groups of COPD patients: EFL at rest, at $1 / 3$ maximal power output (Wmax), and EFL or NFL at 2/3 Wmax. The presence of EFL at rest implies that increased ventilation during exercise should be associated with $\mathrm{DH}$. Indeed, in the COPD patients who were EFL at rest, the EELV increased significantly at both exercise levels studied. Similarly, in the patients who became EFL at $1 / 3$ Wmax, there was a significant increase in EELV only at $2 / 3 \mathrm{Wmax}$. In contrast, in the other patients, there was no significant change in EELV over the entire exercise range studied. The five COPD patients who were EFL from rest
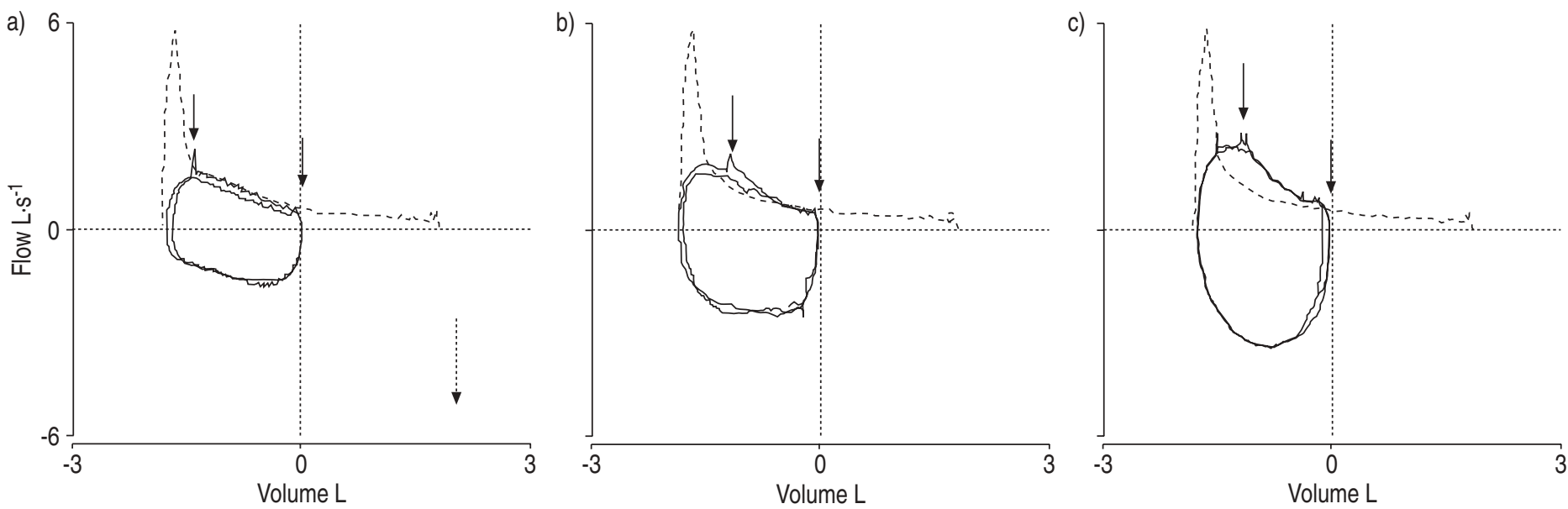

FIGURE 5. Flow-volume curves obtained in a patient with chronic obstructive pulmonary disease a) at rest and at two different levels of exercise: b) $1 / 3$ maximal power output ( $W_{\max }$ and c) 2/3 Wmax. Zero volume represents the end-expiratory lung volume at rest. In each instance, the flow-volume loops of two consecutive breathing cycles are shown: that of a test breath during which negative pressure (NEP) of $-5 \mathrm{cmH}_{2} \mathrm{O}$ was applied during expiration and that of the preceding control breath. NEP was applied during early expiration (first arrow) and maintained throughout expiration (second arrow). With NEP, flow increased at rest but not during exercise, indicating that expiratory flow limitation (ELF) was present at both levels of exercise but not at rest. The expiratory flow-volume curve obtained during a forced vital capacity manoeuvre is also shown (----); using this test the patient would be classified as ELF at rest and during exercise. Figure reproduced with permission from [24] 

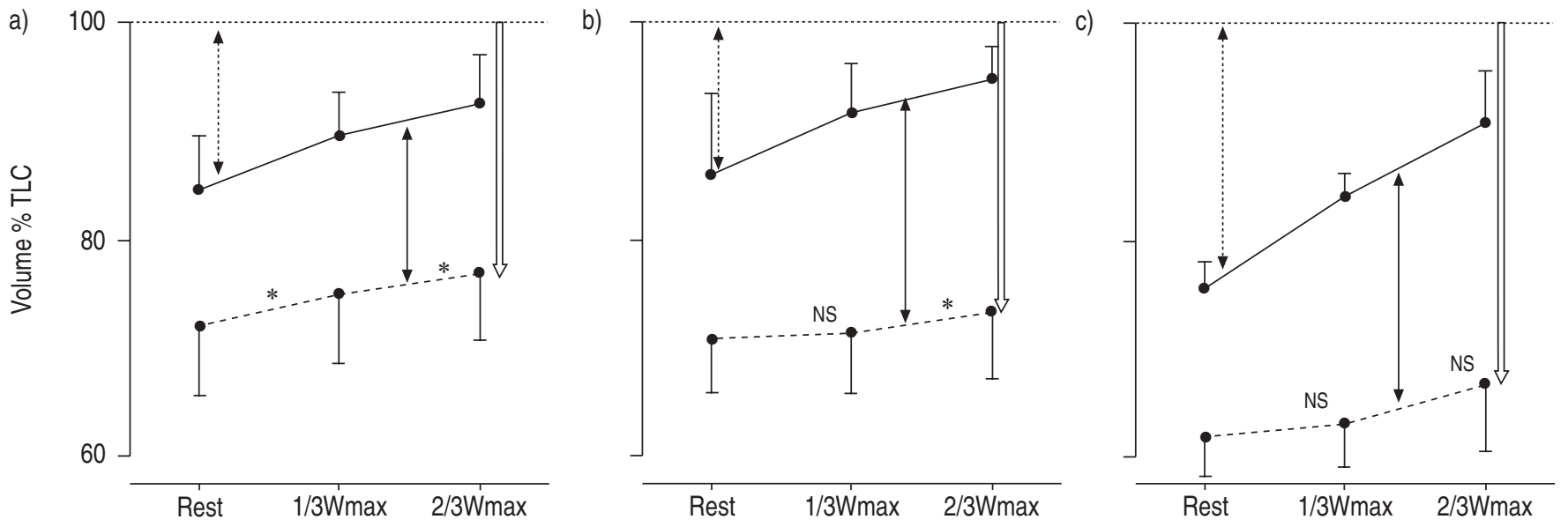

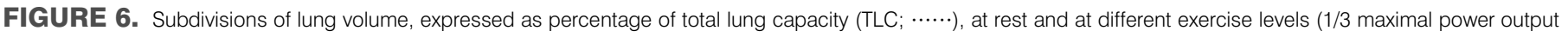

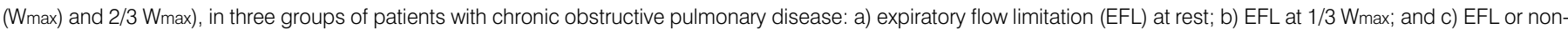

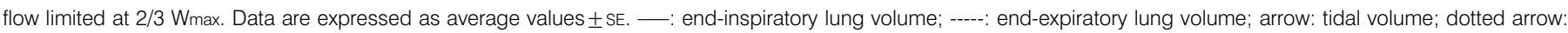
inspiratory reserve volume; open arrow: inspiratory capacity. ${ }^{*}: p<0.05$; NS: nonsignificant. Figure modified from [24].

exhibited a significantly lower IC \% pred than the other COPD patients. If flow limitation is present at rest, with a concomitant decrease in IC, the maximal tidal volume during exercise should also be reduced. Indeed, a very low maximal tidal volume was a characteristic feature of the five COPD patients who were EFL from rest. Therefore, the lower the resting IC the lower the maximal tidal volume attained.

DIAZ et al. [49] found that IC was the only spirometric parameter in which there was almost no overlap between NFL and EFL COPD patients, and the NFL patients had almost all normal IC whilst the EFL all had $<80 \%$ pred in a group of 52 COPD patients. Furthermore, they documented a close correlation between maximal tidal volume and IC $(r=0.77$, $\mathrm{p}<0.0001$ ). In his group of COPD patients, DiAz et al. [50] also confirmed the current authors' initial observation in a smaller group of COPD patients, that maximal tidal volume is closely correlated with exercise capacity [24].

Hence, it was not surprising that linear regression analysis performed separately for EFL and non-EFL patients showed that, in the EFL patients, the sole predictor of exercise capacity was IC \% pred, whilst in the NFL the ratio FEV1/FVC \% pred was the sole predictor. The significant correlation of maximal oxygen uptake with FEV1/FVC ratio in patients without EFL is mainly due to the fact that a high FEV1/FVC ratio reflects a MEFV curve with an upward convexity, which implies a large flow reserve beyond the resting tidal volume range, while a low FEV1/FVC ratio reflects a curve with an upward concavity with little expiratory flow reserve over the resting tidal volume range. Thus, patients without EFL at rest but with a low FEV1/ FVC ratio are more prone to develop EFL during exercise than patients in whom this ratio is high. Development of EFL during exercise limits maximal tidal volume and, hence, maximal exercise ventilation and exercise tolerance. Accordingly, in COPD patients without EFL at rest, maximal oxygen uptake correlates directly with FEV1/FVC \% pred. Therefore, the main finding of these studies was that detection of EFL at rest plays an important role in identifying the factors that limit exercise tolerance, because resting EFL clearly separates two populations of patients with significant differences in exercise tolerance. More importantly, their detection provides useful information about the mechanisms limiting exercise tolerance. In the presence of EFL, DH appears to be the main determinant of exercise performance, and the magnitude of resting IC, a well recognised marker of $\mathrm{DH}$, appears to be the best clinical predictor.

Similarly, a recent study showed that most patients with stable asthma exhibit tidal EFL and DH during exercise, even if their baseline FEV1 and peak expiratory flow are within normal limits and they have no exercise-induced asthma [28]. In asthmatics with exercise-induced tidal EFL, the exercise capacity is reduced as a result of $\mathrm{DH}$. This finding has important clinical implications, because it is possible that administration of bronchodilators immediately before exercise may abolish tidal EFL and DH during exercise and improve exercise capacity.

However, it should be noted that during metacholine (MCh)induced bronchoconstriction, $\mathrm{DH}$, as reflected by decreased IC, commonly occurs in the absence of tidal EFL. Therefore, DH can occur in the absence of EFL, and presence of EFL may not necessarily result in $\mathrm{DH}$ if the available expiratory flow is sufficient to sustain resting ventilation without the need to increase EELV. This is reflected by the fact that there are patients with EFL and normal IC.

In contrast, it has been found that, during exercise, $\mathrm{DH}$ was closely associated with tidal EFL not only in COPD [24] but also in asthmatics [28]. This discrepancy may be due to the fact that, during $\mathrm{MCh}$ challenge, $\mathrm{DH}$ is attributed to increased expiratory resistance associated with persistent activity of the inspiratory muscles during the breathing cycle and expiratory narrowing of the glottis. While some of these mechanisms may have contributed to the exercise-induced DH seen in patients, EFL seems to be the principal factor, since it was present in all patients who exhibited $\mathrm{DH}$ while it was absent in all patients who did not exhibit $\mathrm{DH}$. It is possible that the exercise-induced bronchoconstriction within the lungs is more homogeneous 
than MCh-induced bronchoconstriction. With nonhomogeneous bronchoconstriction, some regions may develop EFL with concurrent $\mathrm{DH}$, while others empty normally; hence, overall EFL (as measured with NEP) may be absent. In such cases, IC may be decreased in the absence of overall EFL. In contrast, with homogeneous bronchoconstriction, overall EFL and $\mathrm{DH}$ should reflect the homogeneously distributed mechanical impairment within the lungs [28].

The NEP technique has also been used to detect flow limitation in mechanically ventilated patients [7, 8, 23, 30-32]. In fact, at first, the NEP method was applied and validated during mechanical ventilation in different body postures [23]. It was found that almost all COPD patients who require mechanical ventilation are flow limited over the entire range of tidal expiration and that the supine posture promotes flow limitation. It should be noted that flow limitation is reversed in lateral decubitus and on hands and knees positions in spontaneously breathing COPD patients [27]. Other studies have shown that most patients with acute respiratory failure of pulmonary origin present tidal EFL, whilst ones with acute respiratory failure of extra-pulmonary origin did not [30]. The same authors found that most acute respiratory distress syndrome (ARDS) patients exhibit EFL, probably associated with small airways closure and a concomitant PEEPi [7]. The presence of EFL, which implies concurrent cyclic dynamic compression and re-expansion of the airways, increases the risk of low lung volume injury. In all ARDS patients, during application of $10 \mathrm{cmH}_{2} \mathrm{O}$ of PEEP, EFL was abolished and the arterial oxygenation was improved satisfactorily because of alveolar recruitment in NFL patients and reduced intrapulmonary PEEPi inequality in EFL patients [8].

Tidal EFL and PEEPi are also common in supine morbidly obese sedated-paralysed subjects after abdominal surgery [32]. This implies that the therapeutic administration of external PEEP to such patients must be monitored with concurrent assessment of EFL and PEEPi. The presence of EFL and peripheral airway closure implies a possible risk of low volume injury. Accordingly, it seems prudent to apply PEEP also in order to avoid peripheral airway closure and EFL.

Therefore, the assessment of EFL in mechanically ventilated patients with the NEP technique is a potentially useful bedside approach to provide information concerning respiratory mechanics.

In the past, there was no online method available to assess whether the flows during the FVC manoeuvres were maximal or not. Recently, however, a simple method to assess FVC performance has been developed [26, 51]. It is based on a variation of the NEP technique, i.e. application of short NEP pulses of $-10 \mathrm{cmH}_{2} \mathrm{O}$ during the FVC manoeuvre. If the expiratory flow increases during the application of the NEP pulse, the expiratory flow is sub-maximal. In contrast, if flow does not increase with the negative pressure, EFL has been reached. Thus, with this method, it is possible to determine whether the maximal flows are low as a result of insufficient respiratory effort (e.g. weak respiratory muscles, lack of coordination, malingering) or the presence of a lung disorder.

In conclusion, the NEP technique has been used clinically in studies with the following: 1) COPD (during mechanical ventilation and exercise, correlation with dyspnoea, orthopnoea, and other lung function indexes, before and after bronchodilatation, various postures) [22-25, 27, 33, 42, 43, 49, 50]; 2) asthma (stable asthma, during MCh bronchocostriction, and during exercise) $[28,44-46]$; 3) cystic fibrosis $[52,53]$ and bronchiectasis [54]; 4) restrictive lung disease [33, 37]; 5) obesity $[32,55,56] ; 6)$ mechanically ventilated with acute respiratory failure and ARDS [7, 8, 23, 30-32]; 7) left heart failure [57]; 8) after single lung transplantation [29, 58]; 9) euthyroid goitre [59]; and 10) assessment of bronchial hyperreactivity [60]. It appears that the use of the NEP technique during tidal flow-volume analysis studies has led to the realisation of the important role of EFL in exertional dyspnoea and ventilatory impairment for a surprisingly wide range of clinical circumstances [61]. Therefore, the NEP technique should be regarded as a new useful research and clinical lung function tool.

In conclusion: 1) application of the NEP technique provides a simple, rapid, noninvasive and reliable test to detect tidal EFL [61-63] ; 2) it does not require a body-box or any cooperation on the part of the patient; 3 ) it can be applied in any body position, during mechanical ventilation and during exercise; 4) it may provide new insights in the physiology and pathophysiology of several diseases and the symptom of dyspnoea.

\section{Alternative approaches}

Although the NEP technique is the most widely used noninvasive test of EFL, it is not the only one available. Workers in Brussels, Belgium, have shown that manual compression of the abdomen coinciding with the onset of expiration can be used as a simple way of detecting flow limitation at rest and during exercise [64, 65]. With one hand placed on the lower back of the patient and other applied with the palm at the level of the umbilicus, perpendicular to the axis between the xiphoid process and the pubis, the operator first detects a respiratory rhythm by gentle palpation and then, after warning, the subject applies a forceful pressure at the onset of expiration. As in the NEP technique, the resulting expiratory flow-volume loop recorded at the mouth is superimposed on the preceding tidal breath. Failure to increase expiratory flow indicates EFL. This technique produces clear differences between normal subjects and patients with COPD. The presence of EFL detected during exercise in COPD patients was associated with increases in the EELV. Interestingly, not all subjects with COPD exhibited EFL when lung volume changed, a finding which requires confirmation in other series. The method is appealingly simple, overcomes problems with the preceding volume history of the test breath and is not influenced by the upper airway compliance. Despite initial concerns about the possibility that gas compression in the alveoli would produce false-positive results, this does not seem to be a practical problem. However, it can be extremely difficult to determine whether EFL is occurring for the whole or part of the preceding breath, unless the timing of the technique is very precise. Like the NEP approach, breath-to-breath variation in EELV can produce contradictory results, as the method assumes that EELV is always constant. Thus far, this technique has not been widely applied despite its relative simplicity. 
The most recent approach to detecting EFL during tidal breathing has been to use the forced oscillation technique previously applied to look at the frequency dependence of resistance in a range of lung diseases and now available commercially in a modified form using impulse oscillometry. However, to date, only one study with this method has been reported, although it does appear to hold considerable promise [66]. The principle here is that EFL will only be present in patients with obstructive pulmonary disease during expiration. Normally oscillatory pressures generated by a loudspeaker system at the mouth are transmitted throughout the respiratory system and, by studying the resulting pressures which are in and out of phase with the signal, both the respiratory system resistance and reactance (a measure of the elastic properties of the system) can be computed [66]. When EFL occurs, wave speed theory predicts that a choke point will develop within the airway subtended by that "unit" of the lung [67]. In these circumstances the oscillatory pressure applied at the mouth will no longer reach the alveoli and the reactance will reflect the mechanical properties of the airway wall rather than those of the whole respiratory system. As a result, reactance becomes much more negative and there is a clear within-breath difference between inspiration and expiration (fig. 7). DellacA et al. [68] used this property to investigate the distribution of changes in within-breath reactance in normal subjects and COPD patients who were instrumented with balloon catheters. These latter allowed a comparison of flow limitation using this new method with the classical Mead-Whittenberger method [10], directly relating alveolar pressure to flow. Although this latter technique also proved to have limitations and, specifically, could not exclude the presence of EFL at low lung volumes, the authors were able to obtain a clear separation between flow-limited and non-flow-limited breaths using a number of indices of withinbreath reactance. In contrast, within-breath resistance showed little fluctuation and did not permit the identification of flowlimited breathing. Some subjects showed consistency in the presence of flow limitation on every breath tested, while others had a more variable pattern, presumably reflecting spontaneous fluctuation in EELV. Although within-breath reactance changes are likely to be detecting EFL, a role for airway closure during tidal breathing cannot be completely excluded. This is a problem for all of the current tests designed to identify EFL.
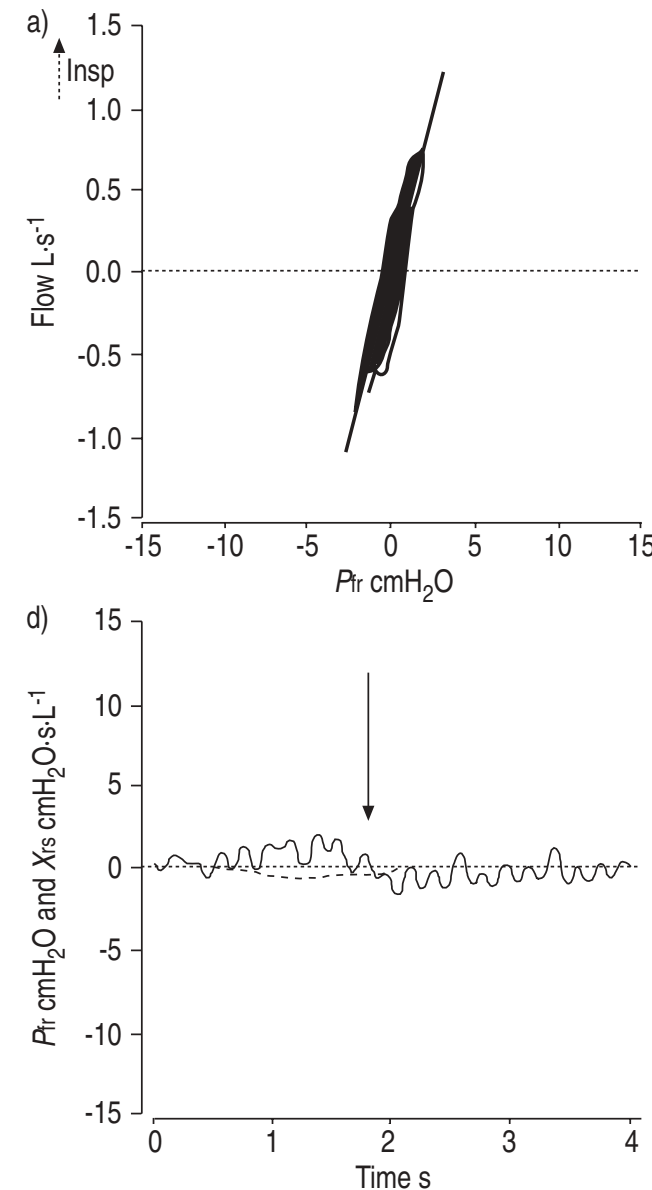
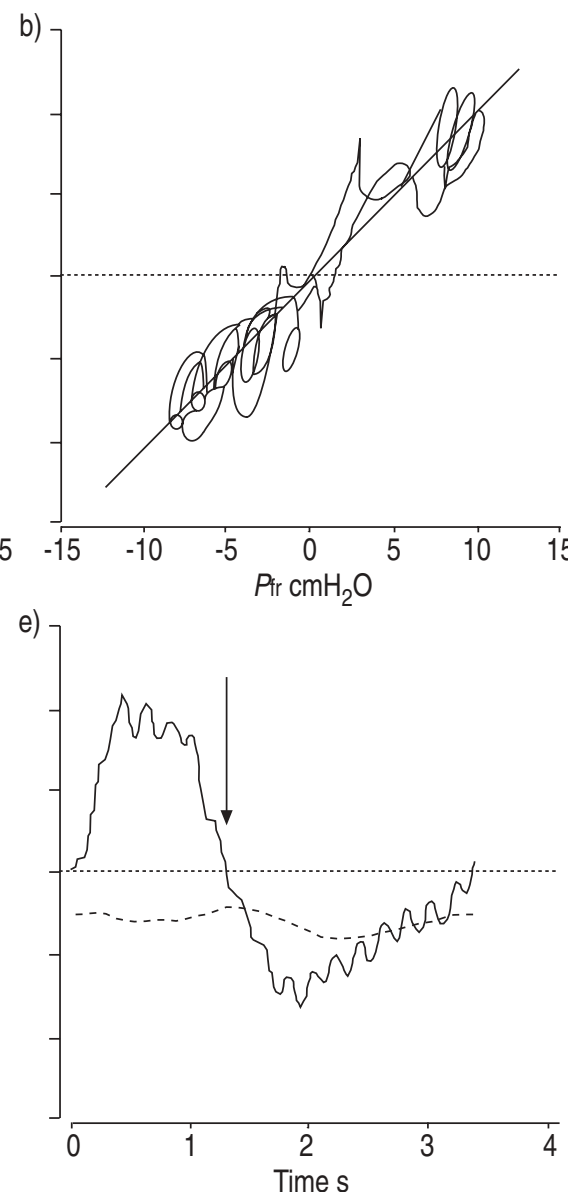
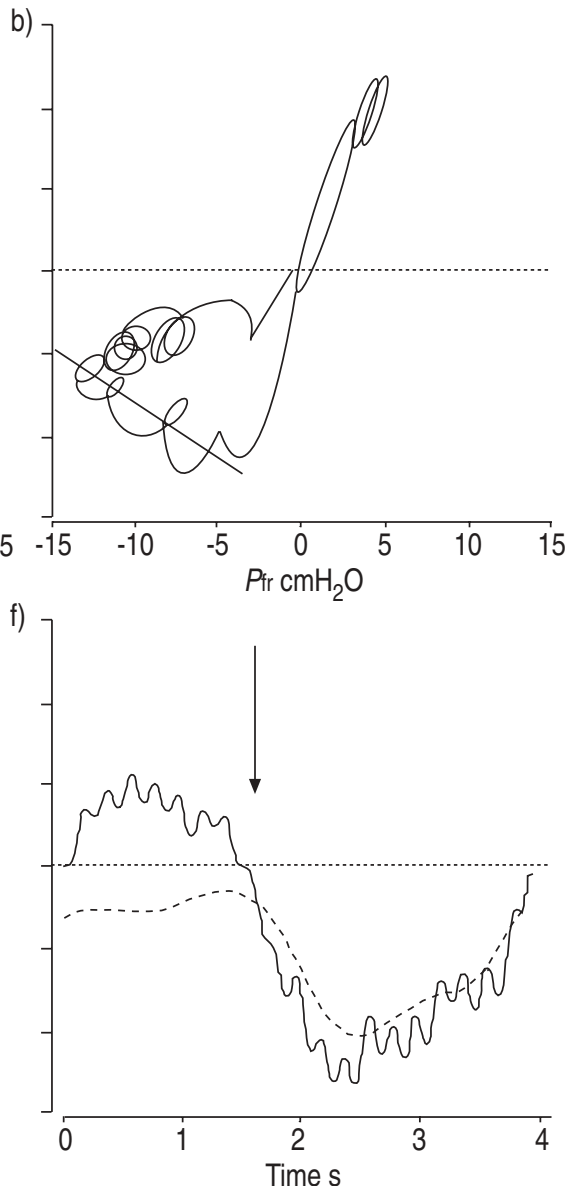

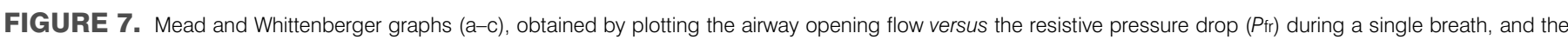

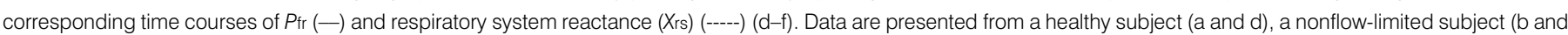

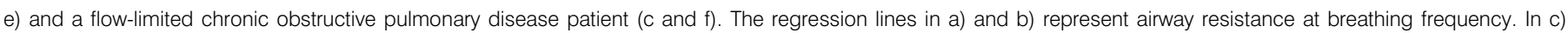

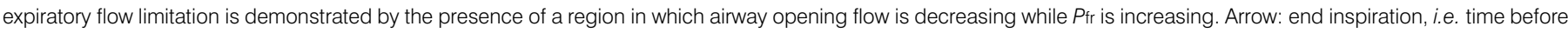
arrow is inspiration, afterwards is expiration. Reproduced with permission from [66] 
Like the other methods, this technique is independent of the previous volume history of the breath tested; however, unlike them it can give breath-by-breath data continuously and provide an aggregate estimate of the probability of flow resistance being present in an individual. It can be used easily during exercise and, perhaps most importantly of all, can be automated, which offers more widespread application for the simple detection of expiratory flow resistance in the intensive care unit and routine physiology laboratory.

Clearly, comparison between these different methods will be needed before the best combination of testing methods can be determined. All of them represent a substantial advance on traditional approaches, which compared tidal and maximal flow-volume loops or even the more robust but timeconsuming method of determining partial expiratory flowvolume loops. By freeing both the doctor and the patient from the confines of the body plethysmograph, a new era has been opened up in the understanding of the important principles of flow limitation in a wide variety of settings.

\section{DYNAMIC HYPERINFLATION}

Although many people are now familiar with the term $\mathrm{DH}$, there is, as yet, no rigorous definition of exactly what this term really means. The observations which led to the study of $\mathrm{DH}$ in recent times began when it was noted that patients with airflow obstruction who were being mechanically ventilated would continue to exhale for a longer period of time than that determined by the ventilator settings [4]. Initially, attention focussed on the deleterious effects of this on cardiac output and, by analogy with adding PEEP, this phenomenal was termed PEEPi. A long and sometimes heated argument followed about the optimal way in which this could be measured in patients whose abdominal muscles were also active during expiration $[69,70]$. Calculations of the increased work of breathing due to this phenomena indicated that there was a substantial elastic burden being placed on the respiratory muscles [71] and this was also present when PEEPi was observed in spontaneously breathing COPD patients. Subsequently, the degree of PEEPi was found to relate to the severity of resting hypercapnia [72].

More recently, the focus of attention has shifted to the increase in EELV that accompanies this phenomenon in spontaneously breathing patients with obstructive lung disease. This was noted to be a common finding in patients with COPD during exercise $[73,74]$ and one that related to the intensity of their breathlessness during exercise [75]. These studies were made possible by the development of reliable methods of measuring IC during exercise [76], when TLC appears to be constant [77]. In these circumstances, any change in IC should reflect a change in EELV. Usually, EELV falls at the onset of exercise to allow the respiratory system to remain on the steeper portion of the pressure-volume relationship and avoid the flatter upper part of this relationship, where any further increase in pressure no longer generates volume change [78]. This does not occur in COPD patients during exercise (fig. 6) with a series of deleterious consequences. These include mechanical limitation of the ability to increase tidal volume and also the need for the respiratory system to operate at a higher lung volume, both of which require a greater percentage of the inspiratory reserve capacity of the respiratory muscles to sustain. The inspiratory muscles can no longer develop force as effectively as at lower lung volumes because of shortening of their initial operating length and they are more likely to develop inspiratory muscle fatigue or approach that state [79], which itself increases volume-related increases in the sensation of breathlessness [80]. As metabolic drive increases with exercise and tidal volume is constrained, the only strategy available is to increase respiratory frequency, which, unfortunately, further decreases expiratory time and reduces the patient's ability to achieve the elastic equilibrium volume. Hence, a vicious cycle is set up, which eventually leads to exercise stopping prematurely, primarily because of exertional breathlessness [81].

Changes in self-reported breathlessness in this setting relate closely to changes in IC and the relationship between the two is likely to be causal [82]. Certainly, bronchodilator drugs which reduce resting IC also delay the time to peak breathlessness $[83,84]$. This is achieved primarily by their effect on resting IC rather than a change in the slope of the IC-breathlessness relationship, which is now recognised to be hyperbolic [84]. Thus, the term DH now encompasses two slightly different processes: 1) the inability to achieve the true relaxation volume of the respiratory system, whether at rest or during exercise; and 2) the change in EELV which accompanies exercise in certain patients and contributes to exercise limitation and dyspnoea. Clearly these two are closely related but they are not necessarily present in all patients with obstructive lung disease to the same degree.

Measuring EELV indirectly by recording the IC has an appealing simplicity and is an option available in many computerised cardiopulmonary exercise systems. It does not involve complex instrumentation, but the measurement protocol should be practiced at rest before exercise begins. The

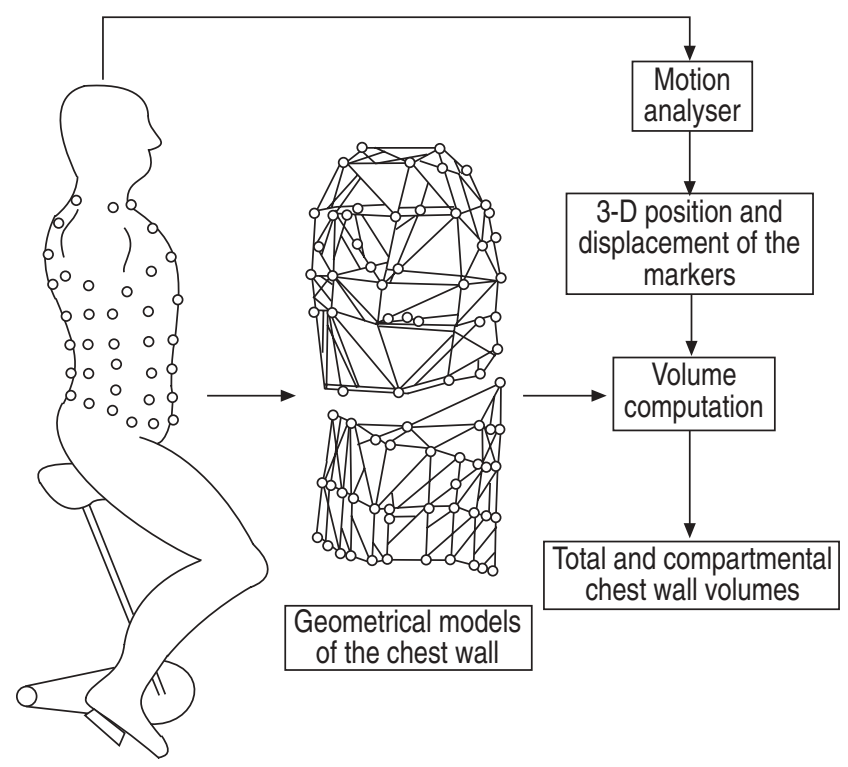

FIGURE 8. Schematic diagram indicating components steps in the analysis of chest wall volume by optoelectronic plethysmography, as applied during exercise. The markers applied to the chest wall permit the construction of the threedimensional (3-D) series of interlinked triangles, which allow the volume of the space they enclose to be calculated. 
system should report breath-by-breath data and/or have a hard copy printout of the original signal, usually obtained by integrating flow from a pneumotachygraph. After a period of stable breathing, the subject is instructed to take as deep a breath in as possible and then breath out normally, the IC being derived directly as the volume changes from end-expiration. In some systems the same data can be obtained by asking the patient to fully breath out (to calculate expiratory reserve volume) and then perform an inspiratory vital capacity; IC being the difference between these two results. The former approach is now more common, but errors can occur if inspiration begins before the patients normal EELV is achieved. The most consistent and probably realistic values are achieved if the mean EELV of the three preceding breaths is used and the breath when the IC manoeuvre is performed is omitted [85].

Several other points should be noted. Data are normally valid only for the relatively few breaths before the IC manoeuvre, as integrator drift precludes extended periods of EELV monitoring using flow at the mouth to measure volume, a particular problem at the higher levels of ventilation seen during exercise. Although most studies assume TLC to be constant during exercise, this has not been confirmed in all circumstances, for instance after bronchodilators, although the major effect here is likely to be on the resting TLC [86]. Finally, the assumption made by most respiratory physiologists that EELV is relatively constant from breath to breath (which is certainly true in anaesthetised cats) is less well studied in conscious humans, especially in those whose lung volumes are dynamically regulated and have a degree of PEEPi at rest. Hence, some physiological, as well as measurement-related, variability is to be expected, although the resting value of IC appears to be almost as reproducible as the FEV1, with a variation between tests of $\sim 200 \mathrm{~mL}$ being reported [48, 87]. Exercise poses a harder problem, given the constantly changing EELV in many COPD patients, and usually only one measurement is made at each workload within a progressive exercise test. Changing EELV can also have implications for the detection of tidal EFL, as the degree of flow limitation may vary with the lung volume adopted and this may be a problem in subjects with potentially severe EFL [48].

Despite these technical limitations, measurement of EELV has provided insight into the mechanisms of exercise-related breathlessness in COPD [73], the effects of bronchodilators on apparently irreversible airflow obstruction [74], the development of hypercapnia in COPD patients during exercise [88],
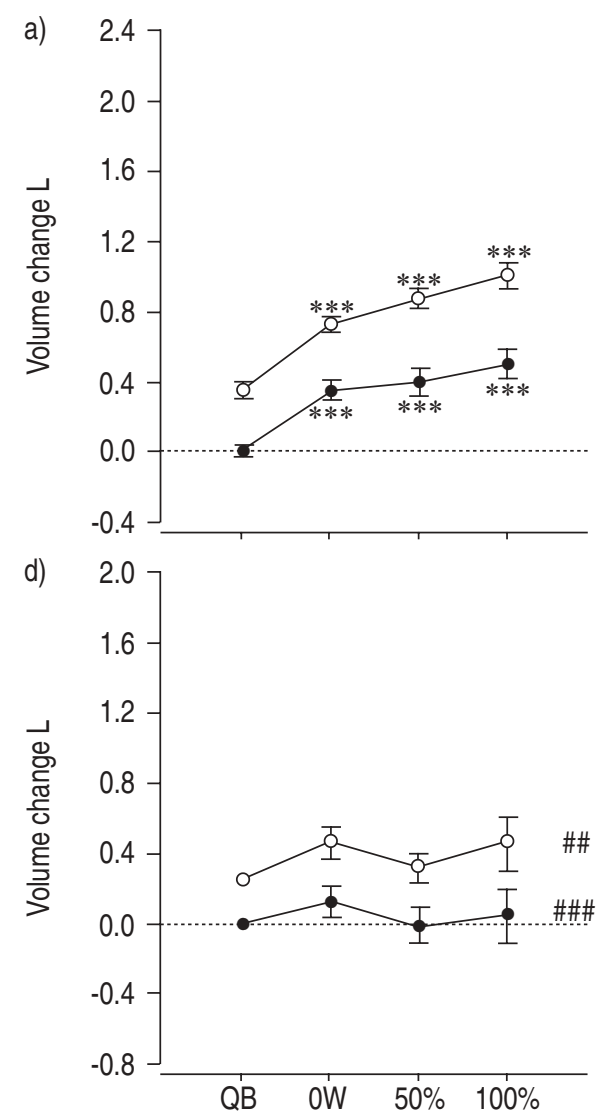
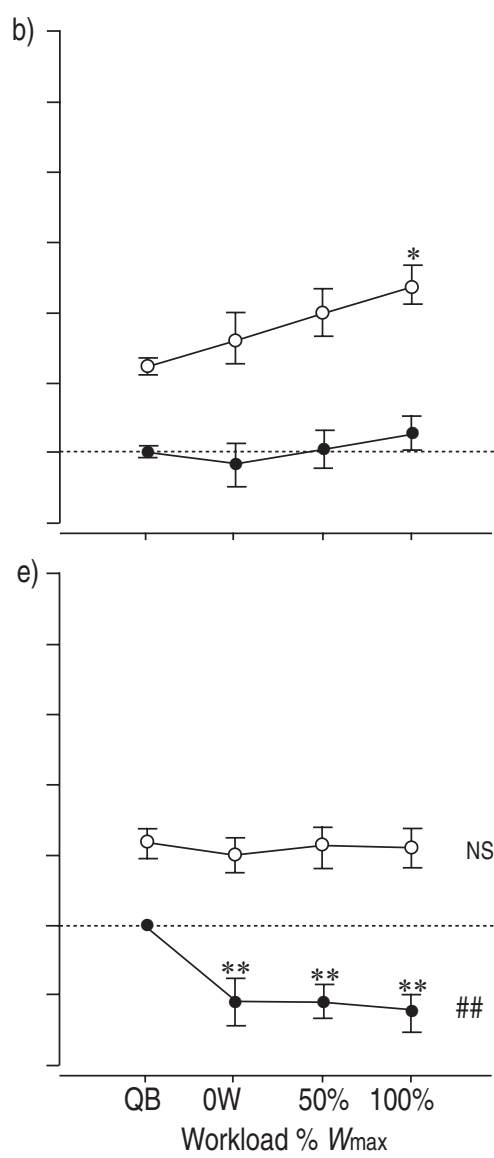
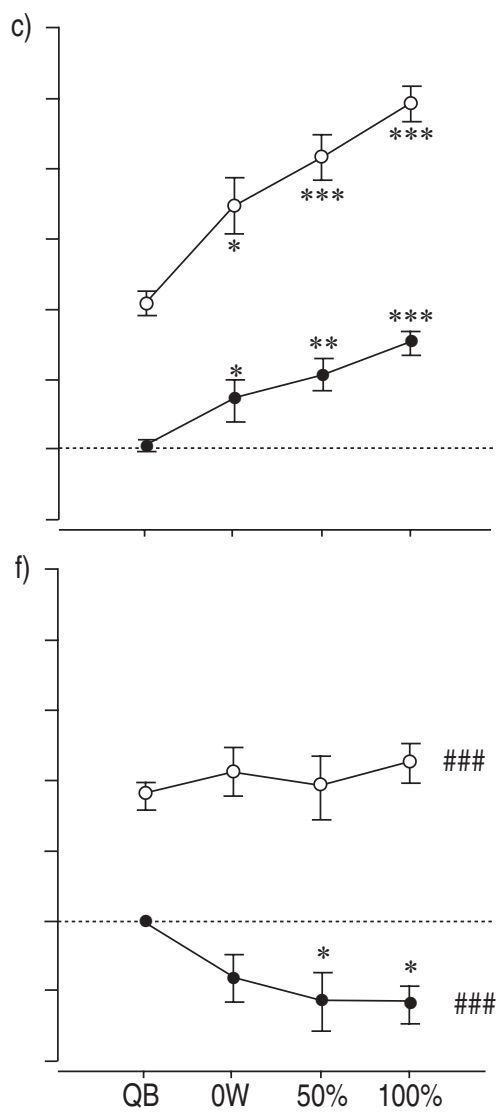

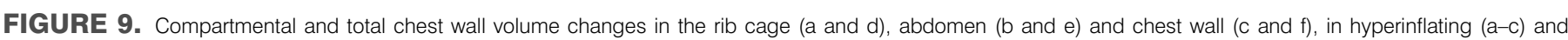

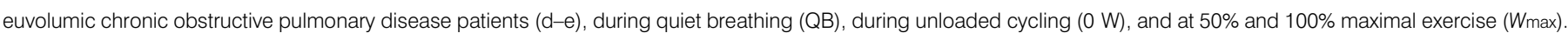

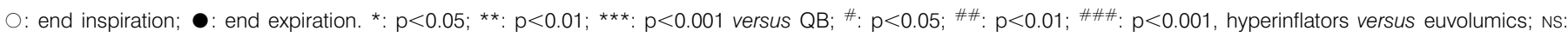
nonsignificant. Reproduced with permission from [101]. 
the mechanisms of action of oxygen and lung volumereduction surgery in the improving exercise performance [89-91], and, most recently, the effects of breathing heliox mixtures in severe COPD [92]. DH can be detected after walking along the corridor [93] and is normally assumed to be the result of EFL [50], although this is not always the case (see above).

Changes in EELV do not capture all the effects of abnormal respiratory system mechanics on exercise. Studies describing the qualitative change in chest wall volume have used magnetometers to look at the contribution of different chest wall compartments, but these are technically demanding and require considerable subject cooperation [94-96]. Recently, a different approach that measures the volume of the chest wall has being applied in healthy subjects [97-99], patients in ICU [100] and those with COPD at rest and during exercise [101103]. Optoelectronic plethysmography (OEP) is a noninvasive measurement based on computing the volume of the chest wall from a network of points identified by shining infrared light at a series of reflective markers attached to the ribcage and abdomen [104] (fig. 8). Its ability to track the position of each point in space and compute the volume enclosed and the resulting three-dimensional structure allows it to track chest wall volume during quiet breathing and exercise. Normally, the change in volume at the mouth and those occurring with each breath derived from the chest wall signal are the same at rest (in health and COPD patients). This remains true during exercise in healthy subjects, but not if they breathe through a Starling resistor nor is it the case in many COPD patients [99, 101]. In this latter group, the difference between the chest wall volume and that at the mouth reflects the effect of gas compression in the lungs, but also the displacement of blood away from the thorax and into the abdomen. This powerful new tool can track regional chest wall volume change and was able to confirm that patients with more severe COPD showed DH during incremental exercise [101]. However, others, specifically those with a greater expiratory flow reserve at rest (i.e. less likely to be flow limited during exercise) adopted the more "normal" approach of trying to lower EELV when they exercised (fig. 9). This proved to be a poor strategy compared with $\mathrm{DH}$, as they developed very high intra-abdominal pressures and actually had worse exercise performance. The exact relationship between EFL and DH and how individuals learn to adopt the latter strategy will require further study, but the availability of OEP means that this is now possible.

\section{CONCLUSION}

In conclusion, contrary to earlier beliefs, the availability of powerful new physiological tools is letting us ask a range of important new questions in patients and settings where it would have previously been impossible to obtain reliable data. The move beyond the body plethysmograph to instrumentation at the bedside or in the exercise or sleep laboratory serves to emphasise the practical application of these new physiological approaches. Although they are easier and more reliable to apply than older methods, there is still a need to pay careful attention to the way the measurement is made and to be aware of their limitations. However, the surprising findings already available and, specifically, the contribution that the measurement of expiratory flow limitation and dynamic hyperinflation in explaining symptoms like breathlessness, mean that our traditional dependence on the forced expiratory volume in one second as the only measurement of respiratory mechanics worth making is already becoming out of date.

\section{REFERENCES}

1 Pride NB. Tests of forced expiration and inspiration. In: Hughes JMB, Pride NB, eds. Lung Function Tests: Physiological Principles and Clinical Applications. London, WB Saunders, 1999: pp. 3-25.

2 Leaver DG, Pride NB. Flow-volume curves and expiratory pressures during exercise in patients with chronic airways obstruction. Scan J Respir Dis 1971; 77: 23-27.

3 Hyatt RE. The interrelationship of pressure, flow and volume during various respiratory maneuvers in normal and emphysematous patients. Am Rev Respir Dis 1961; 83: 676-683.

4 Pepe PE, Marini JJ. Occult positive end-expiratory pressure in mechanically ventilated patients with airflow obstruction: the auto-PEEP effect. Am Rev Respir Dis 1982; 126: 166-170.

5 O'Donnell DE, Sanii R, Anthonisen NR, Younes M. Effect of dynamic airway compression on breathing pattern and respiratory sensation in severe chronic obstructive pulmonary disease. Am Rev Respir Dis 1987; 135: 912-918.

6 Milic-Emili J. Provocative hypothesis: does mechanical injury of the peripheral airways play a role in the genesis of COPD in smokers? COPD: J Chron Obstruc Pulm Dis 2004; 1: 1-8.

7 Koutsoukou A, Armaganidis A, Stavrakaki-Kalergi C, et al. Expiratory flow limitation and intrinsic positive end-expiratory pressure at zero positive end-expiratory pressure in patients with adult respiratory distress syndrome. Am J Respir Crit Care Med 2000; 161: 1590-1596.

8 Koutsoukou A, Bekos B, Sotiropoulou Ch, Koulouris NG, Roussos Ch, Milic-Emili J. Effects of positive endexpiratory pressure on gas exchange and expiratory flow limitation in adult respiratory distress syndrome. Crit Care Med 2002; 30: 1941-1949.

9 D'Angelo E, Pecchiari M, Baraggia P, Saetta M, Balestro E, Milic-Emili J. Low volume ventilation induces peripheral airways injury and increased airway resistance in normal open chest rabbits. J Appl Physiol 2002; 92: 949-956.

10 Mead J, Whittenberger JL. Physical properties of human lungs measured during spontaneous respiration. J Appl Physiol 1953; 5: 779-796.

11 Rodarte J. Invited editorial on "Detection of expiratory flow limitation during exercise in COPD patients". J Appl Physiol 1997; 82: 721-722.

12 Ingram RH Jr, Schilder DP. Effect of gas compression on pulmonary pressure, flow, and volume relationship. J Appl Physiol 1966; 21: 1821-1826.

13 Stubbing DG, Pengelly LD, Morse JLC, Jones NL. Pulmonary mechanics during exercise in subjects with chronic airflow obstruction. J Appl Physiol 1980; 49: 511515.

14 Younes M, Kivinen G. Respiratory mechanics and breathing pattern during and following maximal exercise. J Appl Physiol 1984; 57: 1773-1782. 
15 D’Angelo E, Prandi E, Milic-Emili J. Dependence of maximal flow-volume curves on time-course of preceding inspiration. J Appl Physiol 1993; 75: 1155-1159.

16 D'Angelo E, Prandi E, Marrazzini L, Milic-Emili J. Dependence of maximal flow-volume curves on time course of preceding inspiration in patients with chronic obstructive lung disease. Am J Respir Crit Care Med 1994; 150: 1581-1586.

17 Koulouris NG, Rapakoulias P, Rassidakis A, et al. Dependence of FVC manoeuvre on time course of preceding inspiration in patients with restrictive lung disease. Eur Respir J 1997; 10: 2366-2370.

18 Melissinos CG, Webster P, Tien YK, Mead J. Time dependence of maximum flow as an index of nonuniform emptying. J Appl Physiol 1979; 47: 1043-1050.

19 Fairshter RD. Airway hysteresis in normal subjects and individuals with chronic airflow obstruction. J Appl Physiol 1985; 58: 1505-1510.

20 Wellman JJ, Brown R, Ingram RH Jr, Mead J, McFadden ER. Effect of volume history on successive partial expiratory maneuvers. J Appl Physiol 1976; 41: 153-158.

21 Beck KC, Offord KP, Scanlon PD. Bronchoconstriction occurring during exercise in asthmatic patients. Am J Respir Crit Care Med 1994; 149: 352-357.

22 Koulouris NG, Valta P, Lavoie A, et al. A simple method to detect expiratory flow limitation during spontaneous breathing. Eur Respir J 1995; 8: 306-313.

23 Valta P, Corbeil C, Lavoie A, et al. Detection of expiratory flow limitation during mechanical ventilation. Am J Respir Crit Care Med 1994; 150: 1311-1317.

24 Koulouris NG, Dimopoulou I, Valta P, Finkelstein R, Cosio MG, Milic-Emili J. Detection of expiratory flow limitation during exercise in COPD patients. J Appl Physiol 1997; 82: 723-731.

25 Eltayara L, Becklake MR, Volta CA, Milic-Emili J. Relationship between chronic dyspnoea and expiratory flow limitation in patients with chronic obstructive pulmonary disease. Am J Respir Crit Care Med 1996; 154: 17260-17234.

26 Jones MH, Davies SD, Kisling JA, Howard JM, Castile R, Tepper RS. Flow limitation in infants assessed by negative expiratory pressure. Am J Respir Crit Care Med 2000; 161: 713-717.

27 Dimitroulis J, Bisirtzoglou D, Retsou S, et al. Effect of posture on expiratory flow limitation in spontaneously breathing stable COPD patients. Am J Respir Crit Care Med 2001; 163: A410.

28 Kosmas EN, Milic-Emili J, Polychronaki A, et al. Exerciseinduced flow limitation, dynamic hyperinflation and exercise capacity in patients with bronchial asthma. Eur Respir J 2004; 24: 378-384.

29 Murciano D, Ferretti A, Boczkowski J, Sleiman C, Fournier M, Milic-Emili J. Flow limitation and dynamic hyperinflation during exercise in COPD patients after single lung transplantation. Chest 2000; 118: 1248-1254.

30 Armaganidis A, Stavrakaki-Kalergi K, Koutsoukou A, Lymberis A, Milic-Emili J, Roussos Ch. Intrinsic positive end-expiratory pressure in mechanically ventilated patients with and without tidal expiratory flow limitation. Crit Care Med 2000; 28: 3837-3842.
31 Alvisi V, Romanello A, Badet M, Gaillard S, Philit F, Guerin C. Time course of expiratory flow limitation in COPD patients during acute respiratory failure requiring mechanical ventilation. Chest 2003; 123: 1625-1632.

32 Koutsoukou A, Koulouris N, Bekos B, et al. Expiratory flow limitation in morbidly obese postoperative mechanically ventilated patients. Anesthesiologica Scandinavica 2004; 48: 1080-1088.

33 Baydur A, Milic-Emili J. Expiratory flow limitation during spontaneous breathing. Comparison of patients with restrictive and obstructive respiratory disorders. Chest 1997; 112: 1017-1023.

34 Tantucci C, Duguet A, Ferretti A, et al. Effect of negative expiratory pressure on respiratory system flow resistance in awake snorers and nonsnorers. J Appl Physiol 1999; 87: 969-976.

35 Liistro G, Veritier C, Dury M, Aubert G, Stanescu D. Expiratory flow limitation in awake sleep-disordered breathing subjects. Eur Respir J 1999; 14: 185-190.

36 Verin E, Tardif C, Portier F, Similowski T, Pasquis P, Muir JF. Evidence for expiratory flow limitation of extrathoracic origin in patients with obstructive sleep apnoea. Thorax 2002; 57: 423-428.

37 Baydur A, Wilkinson L, Mehdian R, Bains B, Milic-Emili J. Extrathoracic expiratory flow limitation in obesity and obstructive and restrictive disorders; effects of increasing negative expiratory pressure. Chest 2004; 125: 98-105.

38 Tauber E, Fazekas T, Eichler I, et al. Negative expiratory pressure: A new tool for evaluating lung function in children? Pediatr Pulmonol 2003; 35: 162-168.

39 Grippo A, Carrai R, Romagnoli I, Pinto F, Sanna A. Respiratory-related evoked potential and upper airway transmural pressure change by using the negative expiratory pressure (NEP) device. Clin Neurophysiol 2003; 114: 636-642.

40 Vanpee D, Swine Ch, Delwich JP, Jamart J, Delanois L. Does negative expiratory pressure influence performances of spirometry in older patients? Eur Respir J 2002; 20: 674-678.

41 Vanpee D, Swine Ch, Delwich JP, Delanois L. Evaluation of flow limitation in elderly patients unable to perform a forced expiratory maneuver. Aging Clin Exp Res 2002; 14: 208-211.

42 Eltayara L, Ghezzo H, Milic-Emili J. Orthopnea and tidal expiratory flow limitation in patients with stable COPD. Chest 2001; 119: 99-104.

43 Tantucci C, Duguet A, Similowski T, Zelter M, Derenne JP, Milic-Emili J. Effect of salbutamol on dynamic hyperinflation in chronic obstructive pulmonary disease patients. Eur Respir J 1998; 12: 799-804.

44 Boczkowski J, Murciano D, Pichot M-H, Ferretti A, Pariente R, Milic-Emili J. Expiratory flow limitation in stable asthmatic patients during resting breathing. Am J Respir Crit Care Med 1997; 156: 752-757.

45 Tantucci C, Ellaffi M, Duguet A, et al. Dynamic hyperinflation and flow limitation during methacholineinduced bronchoconstriction in asthma. Eur Respir J 1999; 14: 295-301.

46 Sulc J, Volta CA, Ploysongsang Y, Eltayara L, Olivenstein R, Milic-Emili J. Flow limitation and 
dyspnoea in healthy supine subjects during methacholine challenge. Eur Respir J 1999; 14: 1326-1331.

47 Boni E, Corda L, Franchini D, et al. Volume effect and exertional dyspnoea after bronchodilator in patients with COPD with and without expiratory flow limitation at rest. Thorax 2002; 57: 528-532.

48 Hadcroft J, Calverley PMA. Alternative method for assessing bronchodilator reversibility in chronic obstructive pulmonary disease. Thorax 2001; 56: 713-720.

49 Diaz O, Villafranca C, Ghezzo H, et al. Role of inspiratory capacity on exercise tolerance in COPD patients with and without tidal expiratory flow limitation at rest. Eur Respir J 2000; 16: 269-275.

50 Diaz O, Villafranca C, Ghezzo H, et al. Breathing pattern and gas exchange at peak exercise in COPD patients with and without tidal expiratory flow limitation at rest. Eur Respir J 2001; 17: 1120-1127.

51 Volta CA, Ploysongsang Y, Eltayara L, Sulc J, MilicEmili J. A simple method to monitor performance of forced vital capacity. J Appl Physiol 1996; 80: 693-8.

52 Braggion C, Polese G, Fenzi V, Carli MV, Pradal U, MilicEmili J. Detection of tidal expiratory flow limitation in infants with cystic fibrosis. Paediatr Pulmonol 1998; 25: 213-215.

53 Goetghebeur D, Sarni D, Grossi Y, et al. Tidal expiratory flow limitation and chronic dyspnoea in patients with cystic fibrosis. Eur Respir J 2002; 19: 492-498.

54 Koulouris NG, Retsou S, Kosmas E, et al. Tidal expiratory flow limitation, dyspnoea, and exercise capacity in patients with bilateral bronchiectasis. Eur Respir J 2003; 21: 743-748.

55 Pankow W, Podszus T, Gutheil T, Penzel T, Peter JH, Von Wichert P. Expiratory flow limitation and intrinsic positive end-expiratory pressure in obesity. J Appl Physiol 1998; 85: 1236-1243.

56 Ferretti A, Giampiccolo P, Cavalli A, Milic-Emili J, Tantucci C. Expiratory flow limitation and orthopnea in massively obese subjects. Chest 2001; 119: 1401-1408.

57 Duguet A, Tantucci C, Lozinguez O, et al. Expiratory flow limitation as a determinant of orthopnea in acute left heart failure. J Am Coll Cardiol 2000; 35: 690-700.

58 Murciano D, Pichot ME, Boczkowski J, Sleiman C, Pariente R, Milic-Emili J. Expiratory flow-limitation in COPD patients after single lung transplantation. Am J Respir Crit Care Med 1997; 155: 1036-1047.

59 Torchio R, Gulotta C, Perboni A, et al. Orthopnea and tidal expiratory flow limitation in patients with euthyroid goiter. Chest 2003; 124: 133-140.

60 Wang PH, Kuo PH, Hsu CH, et al. Diagnostic value of negative expiratory pressure for airway hyperreactivity. Chest 2003; 124: 1762-1767.

61 Dueck R. Assessment and monitoring of flow limitation and other parameters fro flow/volume loops. J Clin Monit Comput 2000; 16: 425-432.

62 Milic-Emili J, Koulouris NG, D'Angelo E. Spirometry and flow-volume loops. Eur Respir Mon 1999; 12: 20-32.

63 Johnson BD, Beck KC, Zeballos RJ, Weisman IM. Advances in pulmonary laboratory testing. Chest 1999; 116: 1377-1387.

64 Ninane V, Leduc D, Kafi SA, Nasser M, Houa M, Sergysels R. Detection of expiratory flow limitation by manual compression of the abdominal wall. Am I Respir Crit Care Med 2001; 163: 1326-1330.

65 Abdel KS, Serste T, Leduc D, Sergysels R, Ninane V. Expiratory flow limitation during exercise in COPD: detection by manual compression of the abdominal wall. Eur Respir J 2002; 19: 919-927.

66 Dellaca RL. Measurement of respiratory system impedances. In: Aliverti A, Brusasco V, Macklem PT, Pedotti A, eds. Mechanics of Breathing. Milan, Springer, 2002; pp. 157-171.

67 Dawson SV, Elliott EA. Wave-speed limitation on expiratory flow-a unifying concept. J Appl Physiol 1977; 43: 498-515.

68 Dellaca RL, Santus P, Aliverti A, et al. Detection of expiratory flow limitation in COPD using the forced oscillation technique. Eur Respir J 2004; 23: 232-240.

69 Ninane V, Yernault JC, De Troyer A. Intrinsic PEEP in patients with chronic obstructive pulmonary disease. Role of expiratory muscles. Am Rev Respir Dis 1993; 148 : 1037-1042.

70 Zakynthinos SG, Vassilakopoulos T, Zakynthinos E, Roussos C. Accurate measurement of intrinsic positive end-expiratory pressure: How to detect and correct for expiratory muscle activity. Eur Respir J 1997; 10: 522-529.

71 Pride NB, Milic-Emili J. Lung mechanics. In: Calverley PMA, Pride NB, eds. Chronic Obstructive Pulmonary Disease. London, Edward Arnold, 1995; pp. 69-92.

72 Haluszka J, Chartrand DA, Grassino AE, Milic-Emili J. Intrinsic PEEP and arterial $\mathrm{PCO}_{2}$ in stable patients with chronic obstructive pulmonary disease. Am Rev Respir Dis 1990; 141: 1194-1197.

73 Belman MJ, Botnick WC, Shin JW. Inhaled bronchodilators reduce dynamic hyperinflation during exercise in patients with chronic obstructive pulmonary disease. Am J Respir Crit Care Med 1996; 153: 967-975.

74 O'Donnell DE, Revill SM, Webb KA. Dynamic hyperinflation and exercise intolerance in chronic obstructive pulmonary disease. Am J Respir Crit Care Med 2001; 164: 770-777.

75 O'Donnell DE, Lam M, Webb KA. Measurement of symptoms, lung hyperinflation, and endurance during exercise in chronic obstructive pulmonary disease. Am J Respir Crit Care Med 1998; 158: 1557-1565.

76 Yan S, Kaminski D, Sliwinski P. Reliability of inspiratory capacity for estimating end-expiratory lung volume changes during exercise in patients with chronic obstructive pulmonary disease. Am J Respir Crit Care Med 1997; 156: 55-59.

77 O'Donnell DE, Webb KA. Exertional breathlessness in patients with chronic airflow limitation. The role of lung hyperinflation. Am Rev Respir Dis 1993; 148: 1351-1357.

78 Johnson BD, Reddan WG, Pegelow DF, Seow KC, Dempsey JA. Flow limitation and regulation of functional residual capacity during exercise in a physically active aging population. Am Rev Respir Dis 1991; 143: 960-967.

79 Mador MJ, Kufel TJ, Pineda LA, Sharma GK. Diaphragmatic fatigue and high-intensity exercise in patients with chronic obstructive pulmonary disease. Am J Respir Crit Care Med 2000; 161: 118-123.

80 Yan S. Sensation of inspiratory difficulty during inspiratory threshold and hyperinflationary loadings. Effect of 
inspiratory muscle strength. Am I Respir Crit Care Med 1999; 160: 1544-1549.

81 Man WD, Soliman MG, Gearing J, et al. Symptoms and quadriceps fatigability after walking and cycling in chronic obstructive pulmonary disease. Am J Respir Crit Care Med 2003; 168: 562-567.

82 O'Donnell DE, Bertley JC, Chau LK, Webb KA. Qualitative aspects of exertional breathlessness in chronic airflow limitation: pathophysiologic mechanisms. Am J Respir Crit Care Med 1997; 155: 109-115.

83 O'Donnell DE, Voduc N, Fitzpatrick M, Webb KA. Effect of salmeterol on the ventilatory response to exercise in chronic obstructive pulmonary disease. Eur Respir J 2004; 24: 86-94.

84 O'Donnell DE, Fluge T, Gerken F, et al. Effects of tiotropium on lung hyperinflation, dyspnoea and exercise tolerance in COPD. Eur Respir J 2004; 23: 832840.

85 Dolmage TE, Goldstein RS. Repeatability of inspiratory capacity during incremental exercise in patients with severe COPD. Chest JID - 0231335 2002; 121: 708-714.

86 Newton MF, O'Donnell DE, Forkert L. Response of lung volumes to inhaled salbutamol in a large population of patients with severe hyperinflation. Chest 2002; 121: 10421050.

87 O'Donnell DE, Lam M, Webb KA. Spirometric correlates of improvement in exercise performance after anticholinergic therapy in chronic obstructive pulmonary disease. Am J Respir Crit Care Med 1999; 160: 542-549.

88 O'Donnell DE, D’Arsigny C, Fitzpatrick M, Webb KA. Exercise hypercapnia in advanced chronic obstructive pulmonary disease: the role of lung hyperinflation. Am J Respir Crit Care Med 2002; 166: 663-668.

89 O'Donnell DE, D'Arsigny C, Webb KA. Effects of hyperoxia on ventilatory limitation during exercise in advanced chronic obstructive pulmonary disease. Am J Respir Crit Care Med 2001; 163: 892-898.

90 O'Donnell DE, Webb KA, Bertley JC, Chau LK, Conlan AA. Mechanisms of relief of exertional breathlessness following unilateral bullectomy and lung volume reduction surgery in emphysema. Chest 1996; 110: 18-27.

91 Stevenson NJ, Calverley PM. Effect of oxygen on recovery from maximal exercise in patients with chronic obstructive pulmonary disease. Thorax 2004; 59: 668-672.
92 Palange P, Valli G, Onorati P, et al. Effect of Heliox on lung dynamic hyperinflation, dyspnoea and exercise endurance capacity in COPD patients. J Appl Physiol 2004; 97: 1637-1642.

93 Marin JM, Carrizo SJ, Gascon M, Sanchez A, Gallego B, Celli BR. Inspiratory capacity, dynamic hyperinflation, breathlessness, and exercise performance during the 6minute-walk test in chronic obstructive pulmonary disease. Am J Respir Crit Care Med 2001; 163: 1395-1399.

94 Grimby G, Elgefors B, Oxhoj H. Ventilatory levels and chest wall mechanics during exercise in obstructive lung disease. Scand J Respir Dis 1973; 54: 45-52.

95 Dodd DS, Brancatisano TP, Engel LA. Effect of abdominal strapping on chest wall mechanics during exercise in patients with severe chronic air-flow obstruction. Am Rev Respir Dis 1985; 131: 816-821.

96 Dodd DS, Brancatisano T, Engel LA. Chest wall mechanics during exercise in patients with severe chronic air-flow obstruction. Am Rev Respir Dis 1984; 129: 33-38.

97 Aliverti A, Cala SJ, Duranti R, et al. Human respiratory muscle actions and control during exercise. J Appl Physiol 1997; 83: 1256-1269.

98 Dellaca RL, Aliverti A, Pelosi P, et al. Estimation of endexpiratory lung volume variations by optoelectronic plethysmography. Crit Care Med 2001; 29: 1807-1811.

99 Iandelli I, Aliverti A, Kayser B, et al. Determinants of exercise performance in normal men with externally imposed expiratory flow limitation. J Appl Physiol 2002; 92: 1943-1952.

100 IAliverti A, Dellaca R, Pelosi P, Chiumello D, Pedotti A, Gattinoni L. Optoelectronic plethysmography in intensive care patients. Am J Respir Crit Care Med 2000; 161: 1546-1552.

101 Aliverti A, Stevenson N, Dellaca RL, Lo MA, Pedotti A, Calverley PM. Regional chest wall volumes during exercise in chronic obstructive pulmonary disease. Thorax 2004; 59: 210-216.

102 Duranti R, Filippelli M, Bianchi R, et al. Inspiratory capacity and decrease in lung hyperinflation with albuterol in COPD. Chest 2002; 122: 2009-2014.

103 Bianchi R, Gigliotti F, Romagnoli I, et al. Chest wall kinematics and breathlessness during pursed-lip breathing in patients with COPD. Chest 2004; 125: 459-465.

104 Carnevali P, Ferrigno G, Aliverti A, Pedotti A. A new method for 3D optical analysis of chest wall motion. Technol Health Care 1996; 4: 43-65. 